\title{
MOTIF BATIK KERATON YOGYAKARTA SEBAGAI SUMBER INOVASI PERHIASAN KOTAGEDE
}

\author{
Pandansari Kusumo \\ Titiana Irawani \\ Djandjang Poerwosedjati *)
}

\begin{abstract}
The research aim is to create an innovative, creative and unique jewelry based on batik pattern of Kraton of Yogyakarta. The output in the first year are documentation of geometric, non geometric pattern and innovative jewelry design as the results of batik pattern of Kraton of Yogyakarta and silver jewelry using Kotagede's own technique.

Method used on this research namely library method, observation, interview and analysis of qualitative data which represented descriptively as well as experimentation using some sketches. We also apply some possibility using alternative material such as semi precious stone, shell and pearl. Moreover the benefit expected from this research is to endorse the creative industry in Indonesia, especially to foster the jewelry production at Kotagede as the silver center, that no longer active due to some barriers, such as unattractive design.

Some sketches as the result of experimentation and chosen design will be produced in the second year.
\end{abstract}

Keywords: pattern, batik, Yogyakarta, jewelry, Kotagede

\section{ABSTRAK}

Penelitian ini bertujuan untuk menciptakan perhiasan yang inovatif, kreatif dan unik, bersumber dari motif batik Keraton Yogyakarta. Target yang dicapai pada tahun-1 adalah:

(1) Dokumentasi golongan motif geometris, (2) Non geometris, (3) Terciptanya disain-disain perhiasan yang inovatif, hasil perpaduan motif batik keraton Yogyakarta dan perhiasan perak dengan teknik khas Kotagede.

Metode yang digunakan dalam penelitian tahun-1 ini adalah metode studi pustaka, observasi, wawancara, analisa data kualitatif yang disajikan secara deskriptif dan eksperimen yang berupa beberapa sket. Dalam penelitian ini juga dilakukan beberapa kemungkinan penggunaan bahan pendukung lain seperti batu permata, kerang dan mutiara. Manfaat yang diharapkan dari penelitian ini adalah untuk mendukung industri kreatif yang sekarang sedang digalakkan pemerintah, khususnya untuk lebih menggairahkan kembali hasil produksi perhiasan di sentra kerajinan Kotagede yang akhir-akhir ini terlihat lesu karena beberapa kendala, diantaranya akibat kejenuhan disain yang ada.

\footnotetext{
* Pandansari Kusumo (pandansarikusumo@gmail.com), Titiana Irawani, Djandjang Poerwosedjati, Staf Pengajar
} Program Studi Kriya Seni, Jurusan Kriya, Fakultas Seni Rupa, Institut Seni Indonesia Yogyakarta 
Beberapa sket hasil eksperimen dan disain-disain terpilih yang nantinya akan diwujudkan pada tahun ke-2 .

Kata kunci: motif, batik, Yogyakarta, perhiasan, Kotagede

\section{PENDAHULUAN}

Sebagai kota budaya, Yogyakarta dikenal merupakan daerah penghasil kerajinan batik. Produk yang dihasilkan oleh beberapa sentra kerajinan batik merupakan batik yang bersumber dari Keraton Yogyakarta. Batik Keraton Yogyakarta terdiri dari beberapa golongan motif, diantaranya golongan motif geometrik dan golongan motif semen. Golongan motif batik tersebut memiliki keunikan dan identitas lokal yang sangat menarik jika dapat dikembangkan atau diterapkan dalam bentuk lain, misalnya dalam bentuk perhiasan. Dengan adanya pengembangan dan penerapan motif batik dalam bentuk lain tersebut, maka diharapkan dapat melestarikan dan merevitalisasi kekayaan budaya nasional.

Pengembangan motif batik pada perhiasan juga dilakukan sebagai upaya kreatif dan inovatif untuk mendorong produksi industri kreatif perhiasan yang telah ada di Yogyakarta. Selain batik, Yogyakarta juga dikenal dengan kerajinan perhiasan perak yaitu Kotagede. Sentra kerajinan perhiasan perak di Kotagede telah ada sejak zaman Kerajaan Mataram. Produk yang dihasilkan oleh pengrajin Kotagede tidak hanya dipasarkan untuk pasar lokal saja tetapi sudah merambah pasar Luar Negeri. Mekipun begitu, akhirakhir ini produksi kerajinan perhiasan
Kotagede mengalami kelesuan akibat resesi ekonomi di negara-negara barat, kenaikan harga bahan baku perak, serta disain yang monoton.

Berdasarkan hal tersebut diatas, maka sangat penting penelitian yang bertema batik keraton Yogyakarta sebagai sumber perhiasan Kotagede dilakukan, di samping untuk terus melestarikan motif batik Keraton Yogyakarta, juga untuk membantu dan memotivasi para pengrajin perhiasan di Kotagede untuk kreatif serta inovatif mengembangkan disain-disain baru berdasarkan kekayaan budaya lokal Indonesia.

\section{METODE}

Studi Pustaka

Studi Pustaka dilakukan untuk memperoleh data-data yang terkait dengan masalah penelitian selain dari buku data juga diambil dari jurnal, majalah, hasil penelitian ataupun tulisan-tulisan lainnya.

Metode Observasi

Observasi dimaksudkan untuk mengamati secara langsung obyek yang diteliti agar dapat memperoleh gambaran yang kongkrit. Antara lain mengunjungi perpustakaan dan museum keraton Yogyakarta, Museum Sonobudoyo dan perpustakaan ISI Yogyakarta. Selain itu penelitian juga melakukan observasi ke sentra perhiasan Kotagede untuk 
mendokumentasi data-data tentang perkembangan perhiasan yang ada.

Observasi juga melakukan kajian tentang bentuk, fungsi dan makna yang ada di motif batik Jogjakarta. Khususnya motif geometrik dan motif non geometrik.

\section{Metode Wawancara}

Pengumpulan data juga dilakukan dengan metode wawancara pada nara sumber baik di lingkungan kraton maupun di Kotagede yaitu pakar-pakar seniman tradisi kriya, seniman akademisi kriya dan para pendukungnya, terutama untuk mencari informasi tentang motif batik yang berasal dari kraton Jogjakarta dan perkembangan desain perhiasan di Kotagede, juga masalah-masalah yang muncul yang berkaitan dengan desain perhiasan.

\section{Metode Analisis Data}

Setelah data terkumpul kemudian dilakukan analisis data menggunakan metode analisis kualitatif yang disajikan secara deskriptif. Analisis data merupakan upaya untuk mencari dan menata secara sistematis catatan hasil studi kepustakaan, observasi, wawancara, dan lainnya disusun menjadi bentuk hasil penelitian sesuai dengan teritori yang telah ditetapkan dan format atau pedoman penulisan penelitian sesuai dengan ketentuan yang berlaku yang ditetapkan dalam penelitian strategis nasional.

Metode Eksperimen

Metode eksperimen dilakukan untuk mencari bentuk-bentuk baru dengan membuat beberapa sket dan melakukan kemungkinan-kemungkinan mix media dengan beberapa macam bahan seperti logam, kayu dan batu.

Metode Perwujudan

Agar tercapai hasil penciptaan yang maksimal, dilakukan tahapan-tahapan yang sistematis dan terencana dari awal penciptaan sampai pada akhir tahapan perwujudan karya, seperti yang dikemukakan Gustami secara metodelogis proses lahirnya suatu karya melalui tiga tahapan utama, yaitu (1) eksplorasi, meliputi langkah pengembaraan jiwa, dan penjelajahan dalam menggali sumber ide. Dari kegiatan ini akan ditemukan tema dan berbagai persoalan. Langkah kedua adalah menggali landasan teori, sumber dan referensi serta acuan visual untuk memperoleh konsep pemecahan masalah. (2). Perancangan, yang terdiri dari kegiatan menuangkan ide dari hasil analisis yang telah dilakukan ke dalam bentuk dua dimensional, atau disain. Hasil perancangan tersebut selanjutnya diwujudkan dalam bentuk model dan (3) perwujudan, merupakan perwujudan dari model menjadi karya. ( Gustami, Sp.: 2004).

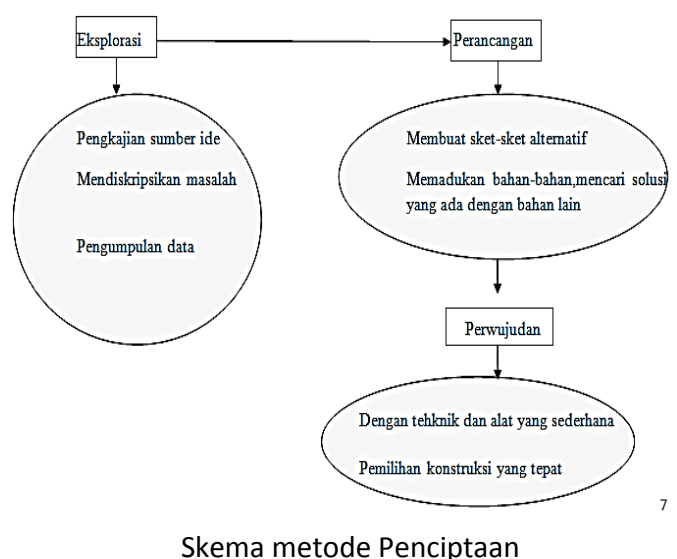

Skema metode Penciptaan 


\section{PEMBAHASAN}

Motif batik Keraton Yogyakarta yang menjadi fokus dalam penelitian ini adalah:

motif batik yang berasal dari Keraton Yogyakarta, dan sampai sekarangi masih digunakan dalam berbagai kegiatan seharihari di Keraton, seperti untuk busana, upacara ritual adat, ritual agama, dan busana Keprabon. A.N. Suyanto mengatakan bahwa batik keraton adalah batik yang tumbuh dan berkembang dilingkungan keraton dengan dasar-dasar filsafat kebudayaan Jawa, yang mengacu pada nilai-nilai spiritual dan pemurnian diri, serta memandang manusia dalam konteks harmoni dengan semesta alam yang tertib, serasi dan seimbang. ( Biranul Anas dalam Suyanto; 2002:28). Dengan demikian makin jelaslah bahwa batik kraton Yogyakarta merupakan manifestasi budaya keraton baik dari aspek bentuk, motif, fungsi dan makna simbolisnya.

Motif batik Keraton Yogyakarta dapat digolongkan menjadi dua jenis, yaitu: motif geometrik dan motif non geometrik. Motif Geometrik adalah motif yang dibuat berdasarkan bentuk-bentuk ilmu ukur, seperti segi 4, segi 3, garis, lingkaran, bidang dan lain-lain. Motif non geometrik adalah motif-motif yang diciptakan tanpa menggunakan kaidah-kaidah ilmu ukur. Dalam penciptaan motif non geometrik ini si pencipta tidak menggunakan pembagian bidang-bidang sebagaimana dalam pembuatan motif batik geometrik. Seniman lebih bebas karena tidak terpaku dalam aturan pengulangan bentuk bidang, motif non geometris banyak berupa bentuk-bentuk fauna dan flora.
Bentuk, fungsi dan makna motif batik keraton masing-masing memiliki karakter sesuai dengan kebutuhan masyarakat pada jamannya, misalnya: motif Parang Rusak Barong hanya boleh dipakai oleh Raja/Sultan, karena bentuknya yang besar diantara motif Parang Rusak yang lain. Adapun motif Parang Rusak Gendreh ukurannya lebih kecil dari Parang Rusak Barong dan digunakan oleh Putra Sultan. Bila ditinjau dari makna simboliknya, pada garis besarnya unsurunsur motif yaang terdapat dalam motif Parang Rusak itu, masing-masing memiliki simbol sendiri-sendiri, antara lain air dan api yang merupakan elemen hidup manusia. Untuk lebih jelasnya bentuk, motif, dan makna batik kraton Yogyakarta diuraikan sebagai berikut:

A. Motif Batik: Bentuk, Fungsi, dan Makna Motif Geometris:

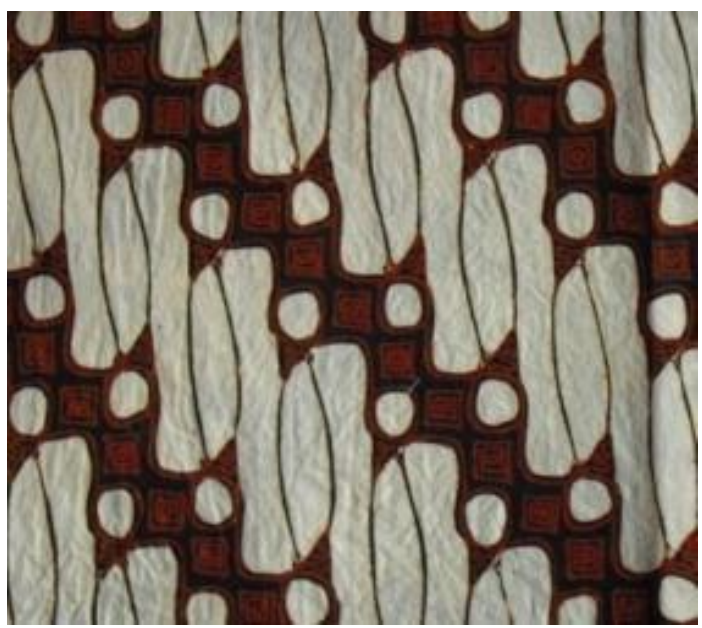

\section{Gb. 1. Motif Parang Rusak}

- Unsur-unsur bentuk Parang Rusak meliputi gubahan motif api atau disebut juga motif parang dan motif Mlinjon yang berbentuk segi empat belah ketupat. 
- Makna simboliknya, pada garis besarnya unsur-unsur motif yang terdapat dalam motif Parang Rusak itu, masing-masing memiliki simbol sendiri-sendiri, antara lain air dan api yang merupakan elemen hidup manusia.

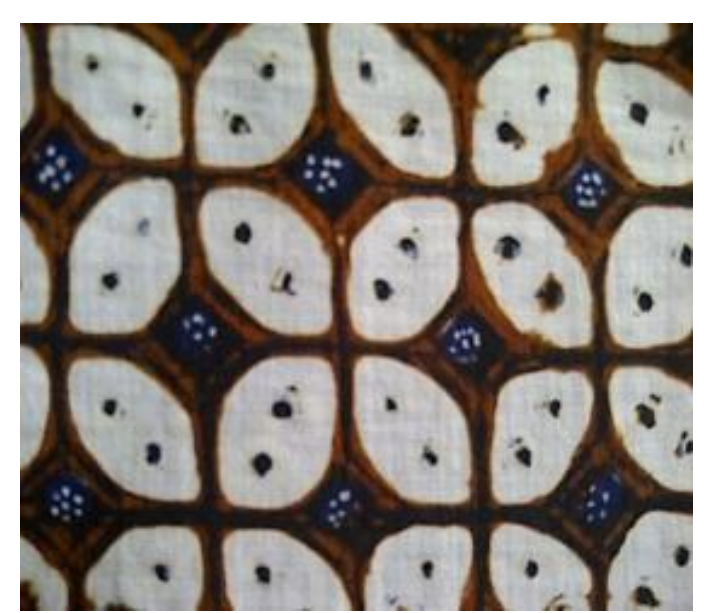

Gb. 2. Motif Kawung

- Dilihat dari bentuknya motif kawung termasuk kelompok motif ceplok dalam golongan motif geometrik. Susunan motifnya terdiri dari unsur motif buah kawung dan mlinjo atau segiempat belah ketupat. Motif kawung tersusun dari bentuk 4 elips membujur diagonal ke kiri dan ke kanan dengan pusat lingkaran yang dibelah secara vertikal dan horisontal. Diantara bentuk elips terdapat bentuk mlinjon.

- Motif kawung dikenakan oleh putraputri Sultan HB VII dan termasuk motif larangan (Mari Condro, 1995;11).

- Sebagai simbol pengharapan si pemakai adalah seorang manusia yang mempunyai bibit unggul yang dalam hidupnya dapat berguna bagi kepentingan nusa bangsa dan negara.

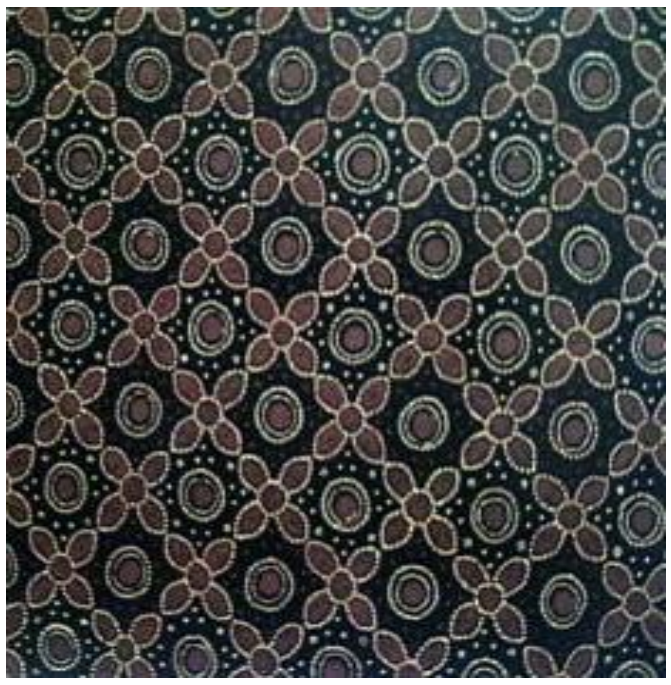

Gb. 3. Motif Grompol

- Motif grompol termasuk gabungan motif ceplok dalam golongan geometrik.

- Bentuk motif bunga berkelopak empat dengan putik ditengah terdiri dari motif, buah yang dikelilingi empat pasang cecek tiga berada ditengah motif segi empat yang berujung 8 .

- Motif ini digunakan dalam upacara perkawinan dan "mitoni", yaitu ketika upacara siraman digunakan oleh pengantin, orangtua pengantin.

- Makna motif grompol sebagai diibaratkan pohon yang sarat dengan bunga dan buah, sebagai simbol harapan agar Tuhan selalu melimpahkan rahmat dan anugerahnya kepada si pemakai motif grompol, selalu hidup tentram, banyak rejeki, banyak anak, hidup rukun dan sejahtera selamanya. 


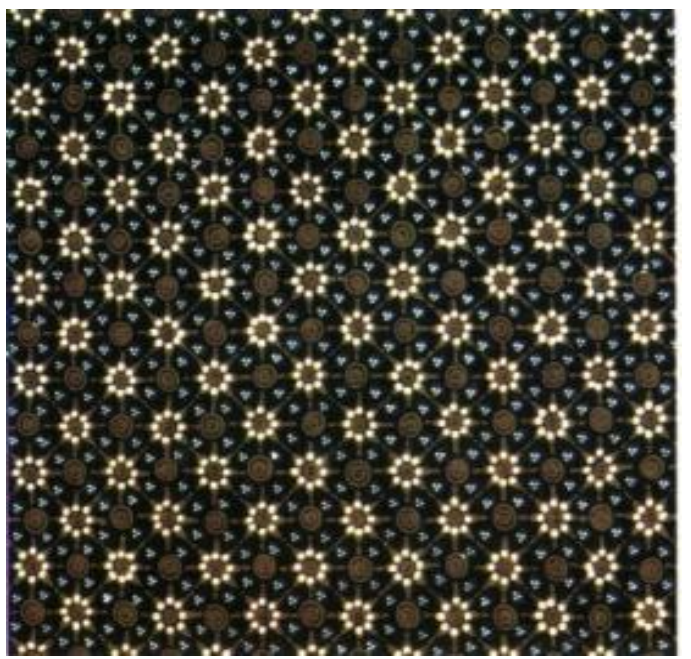

\section{Gb. 4. Motif Truntum}

- Bentuk motif truntum tersusun dari motif bunga kelopak 8 sesuai arah mata angin dengan putik cecek 9 yaitu 8 titik sesuai arah mata angin dengan 1 titik ditengah sebagai pusatnya.

- Fungsi motif ini pada kain dipakai untuk upacara perkawinan pada saat upacara midodareni dan panggih yang dipakai oleh kedua orangtua mempelai.

- Maknanya sebagai simbol bunga gambir yang berkembang berbau harum. Suatu harapan bagi si pemakai motif ini agar dalam berkeluarga hendaknya selalu terjalin hubungan yang harmonis dalam kehidupan suami istri maupun hubungan anak dengan orangtua dalam keluarga sendiri meluas pada keluarga orang lain.

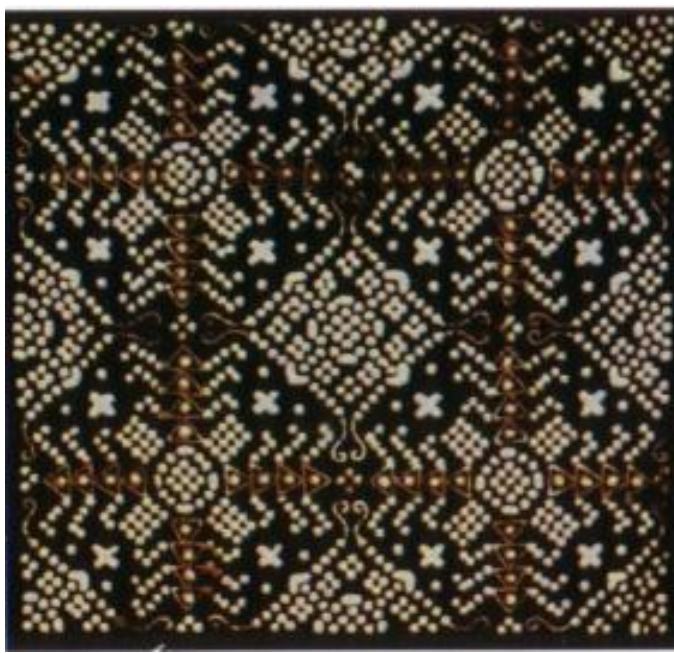

Gb. 5. Motif Cakar Ayam

- Dilihat dari bentuknya motif cakar termasuk kelompok motif nitik dalam golongan motif geometris, motif ini tersusun oleh garis putus-putus, titiktitik kotak dan variasinya sepintas lalu seperti motif anyaman. Bentuk motif cakar terdiri dari motif roset yang berjari-jari 8 dengan titik pusat ditengah tersusun berjajar, sehingga diantara lingkaran-lingkaran tersebut terdapat motif mlinjon.

- Motif nitik cakar digunakan oleh kedua orang tua mempelai pada saat pasang tarub yaitu saat awal dimulainya suatu perhelatan.

- Motif ini sebagai simbol pengharapan bagi si pemakai pandai mencari rejeki. 


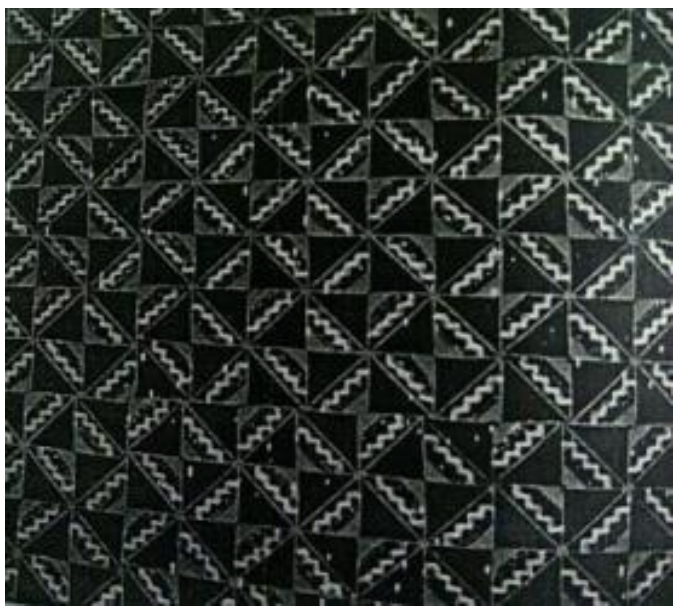

Gb. 6. Motif Slobok

- Melihat bentuknya motif slobok termasuk motif geometrik. Tersusun dari 4 segi tiga sama kaki yang sama dan sebangun, dipertemukan pada masing-masing puncaknya, berwarna hitam dan putih.

- Motif ini digunakan untuk pakaian keprajuritan yang biasanya dipakai oleh prajurit Geladag.

- Motif ini sebagai simbol harapan agar si pemakai diberi kelonggaran atau kemudahan dalam mencapai kenaikan pangkat dan kedudukan.

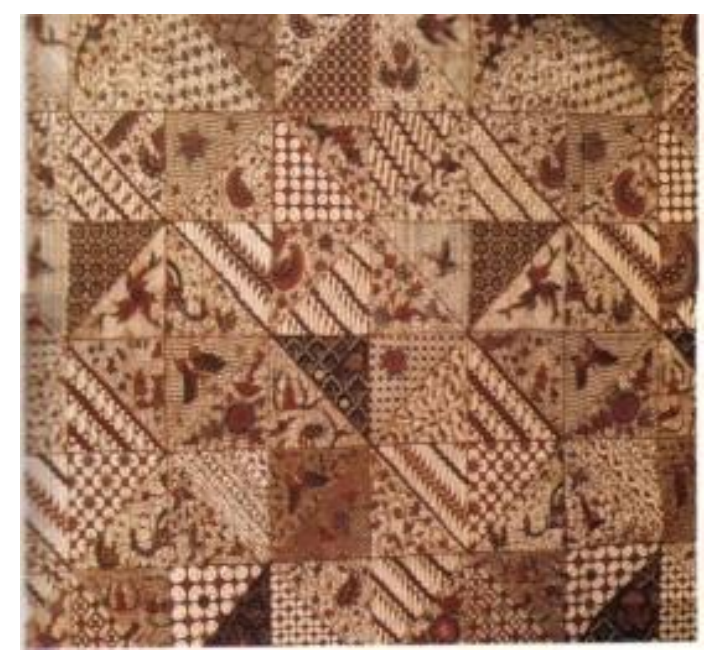

Gb. 7. Motif Tambal
- Dilihat bentuknya motif tambal dapat digolongkan motif geometris. Polanya tersusun dalam bentuk segi empat. Tiap bujur sangkar satu ujungnya ditarik garis diagonal ke ujung yang lain berlainan arah dengan bujur sangkar yang disisi-sisiny, sehingga dalam satu bujursangkar yang paling kecil terdapat dua bentuk segitiga. Bujur sangkar dalam motif tambal ini dapat juga dilihat bentuk bujur sangkar kecil dan membesar tergantung bagaimana menentukan besar kecilnya sisi bujur sangkar.

- Motif tambal sesuai dengan fungsinya digunakan untuk bebet (kain panjang) oleh para abdi dalem sultan yang mempunyai pangkat dalang, pesinden jajar dan geladhag.

- Motif tambal memilliki banyak unsur motif yang masing-masing memiliki makna simbolik, sehingga dari berbagai arti simbolik tersebut dapat diambil intinya yaitu harapan kebahagiaan lahir batin bagi si pemakai meskipun faktor perintang dan keterbatasan setiap saat menghadangnya.

2. Motif Non Geometris

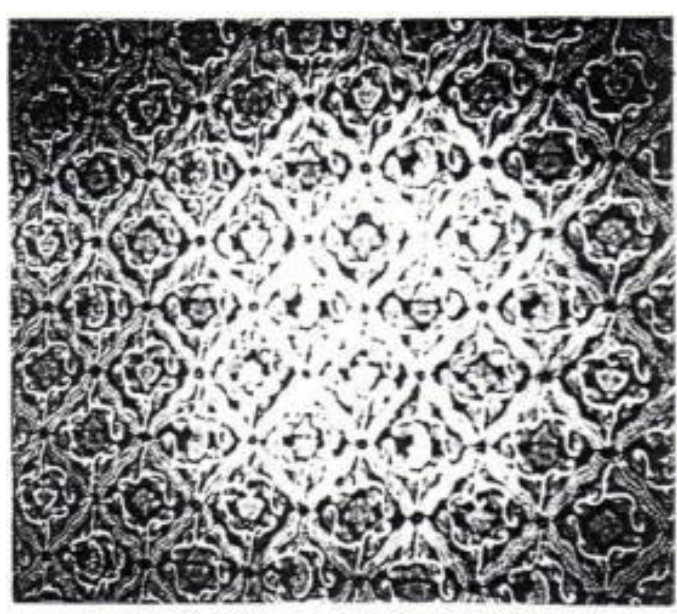

Gb. 8. Motif Semen Sidaluhur 
- Dillihat bentuknya motif sidaluhur digolongkan motif semen. Motif ini tersusun terdiri dari susunan motif meru, pohon hayat, burung, tumbuhtumbuhan dan sawat.

- Motif sidaluhur digunakan untuk busana pengantin pada upacara panggih, kadang-kadang dipakai pula oleh kedua orangtua pengantin.

- Ditinjau dari makna simboliknya motif sidaluhur dapat diuraikan menurut makna simbolik dari unsur-unsur motifnya. Berbagai arti perlambangan yang terdapat dalam unsur-unsur motif sidaluhurnadalah harapan agar hidupnya dapat menjadi bahagia, mempunyai pangkat yang tinggi, dapat berbuat adil, berbudi luhur dan tabah menghadapi segala cobaan hidup.

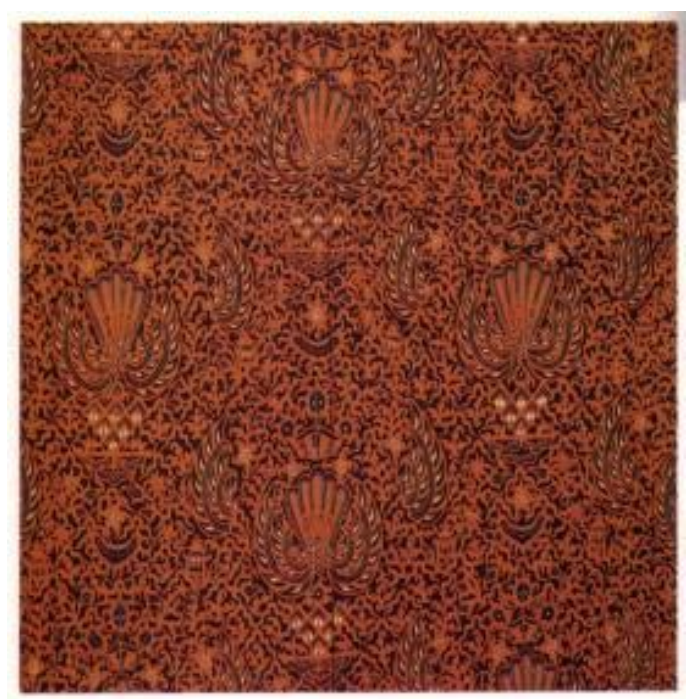

Gb. 9. Motif Semen Ageng Sawat Lar

- Dilihat bentuknya terdiri dari susunan unsur-unsur menu, lidah api, perahu, burung dan sawat.

- Sesuai dengan fungsinya motif ini digunakan oleh cicit dan canggah Sultan, dalam bentuk bebed, bebed keprajuritan dan dodot. Selain itu motif ini dipakai untuk busana keprabon pada upacara adat dan keagamaan di keraton.

- Makna simbolik dari unsur-unsur motif semen Ageng Sawat Lar dapat diuraikan dari motif-motif yang ada di dalamnya. Dari berbagai ungkapan simbolik unsur-unsur motif didalamnya dapat di kemukakan bahwa si pemakai berharap dapat hidup berbahagia di masa mendatang, dapat menjadi pemimpin yang berbudi luhur, lapang dada dan selalu tabah.

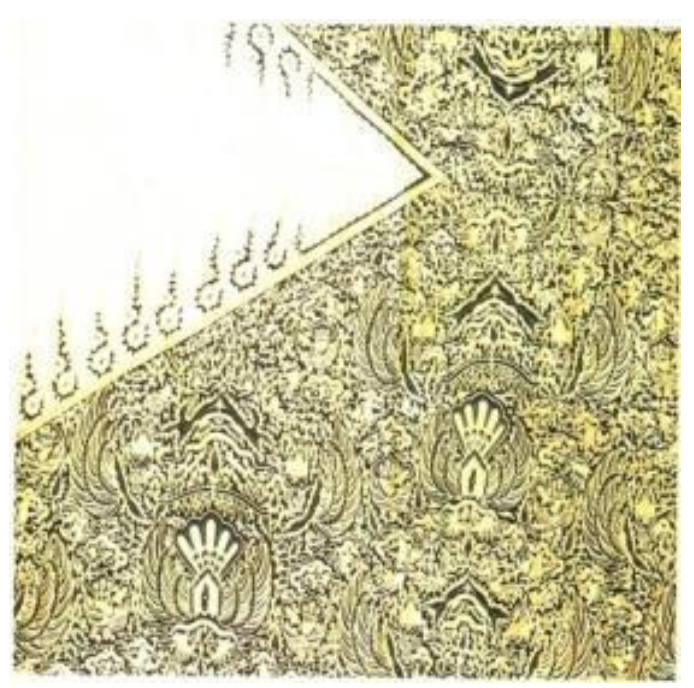

Gb. 10. Motif Semen Ageng Sawat Gurdha

- Dilihat dari bentuknya, motif Semen Ageng Sawat Gurdha merupakan kelompok , dapat dikelompokkan sebagai motif semen. Tersusun dari unsur-unsur motif meru, motif binatang berkaki empat, motif tumbuh-tumbuhan, motif pohon hayat, motif burung, motif sawat dan motif gurdha.

- Motif semen Ageng Sawat Gurdha termasuk pakaian keprabon yang digunakan dalam upacara adat dan 
keagamaan oleh keluarga sultan, mulai dari Kanjeng Panembahan hingga cucu Sultan.

- Makna simbolik Motif Semen Ageng Sawat Gurdha dapat disarikan dari makna simbolik unsur-unsur motif didalamnya. Dapat diungkapkan bahwa si pemakai motif Semen Ageng Sawat Gurdha mempunyai harapan agar hidupnya dapat berbahagia. Apabila dia seorang pemimpin hendaknya mempunyai sifat yang baik, berbudi luhur, berlaku adil, memberi hadiah kepada anak buah dan tabah menghadapi cobaan.

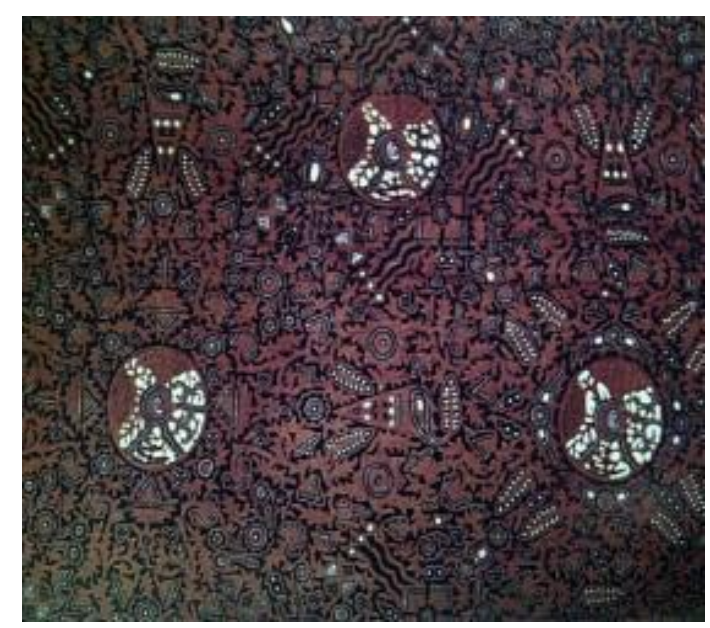

Gb. 11. Motif Semen Huk

- Dilihat dari bentuknya tersusun dari unsur-unsur motif kerang, motif binatang, motif cakra, motif burung huk,motif sawat, dan motif gurdha.

- Motif Semen Huk termasuk motif Larangan dimasa HB VII, yang hanya diperbolehkan dipakai oleh Raja dan putra mahkota.

- Makna motif Semen Huk, dapat disarikan dari unsur-unsur motif didalamnya.Dapat diambil intinya, bahwa si pemakai motif ini mempunyai pengharapan agar hidupnya dapat bahagia, dapat menjadi pemimpin yang berbudi luhur, dapat memberikan kemakmuran kepada rakyat, dapat memimpin keagamaan secara baik, selalu tabah dan melakukan tampuk pemerintahan secara bersungguhsungguh.

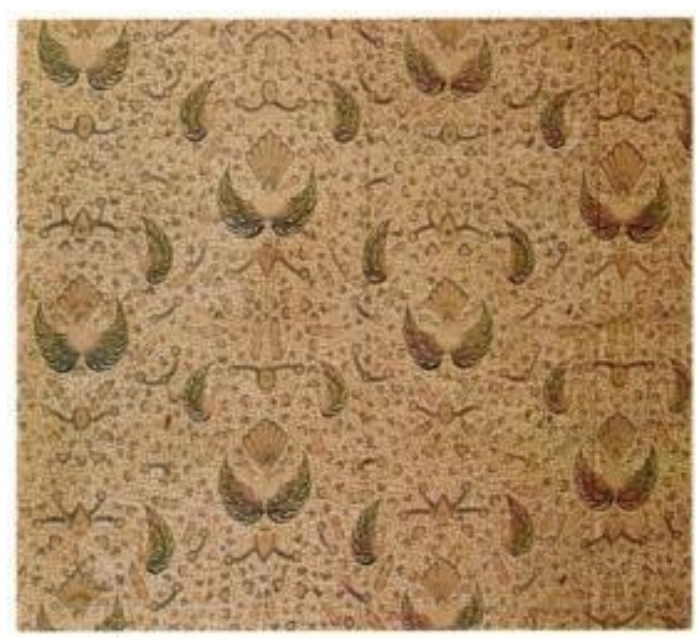

Gb. 12. Motif Semen Sida Mukti

- Dilihat bentuk motifnya terdiri dari beberapa unsur motif yaitu motif kernag, motif pohon hayat, motif burung, motif kerang, motif pohon hayat, motif binatang, motif sawat, motif gurdha.

- Motif ini digunakan pada upacara perkawinan sebagai busana pengantin pada upacara panggih.

- Unsur-unsur motif yang ada pada motif Semen Sida Mukti ini, masing-masing memilki makna simbolik, sehingga secara garis besarnya motif Semen Sida Mukti bagi si pemakai dapat hidup bahagia, makmur dan sentosa, mempunyai kedudukan yang tinggi dan dermawan. 


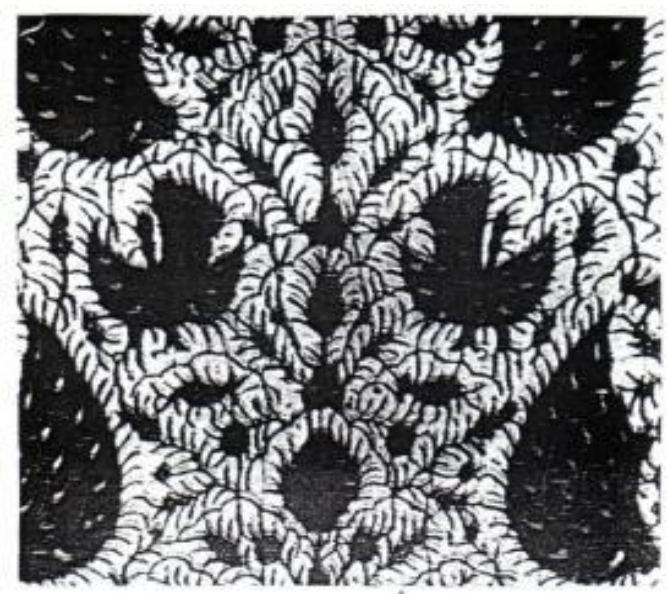

Gb. 13. Motif Sida Asih

- Dilihat bentuknya motif ini susunannya terdiri dari bermacam-macam unsur motif seperti motif pohon hayat, motif burung, motif sawat.

- Sesuai fungsinya, motif sidaasih dipakai pada upacara perkawinan yaitu dipakai oleh pengantin saat upacara panggih.

- Motif sida Asih memiliki makna simbolik dari unsur-unsur motif di dalamnya yang intinya bahwa si pemakai motif ini berpengharapan agar di kemudian hari dapat hidup bahagia, makmur sentosa, saling mengasihi dalam mengarungi bahtera keluarga, berwatak luhur, dikasihi warga masyarakat dan tabah dalam menghadapi cobaan.
B. Sketsa dan Disain Perhiasan

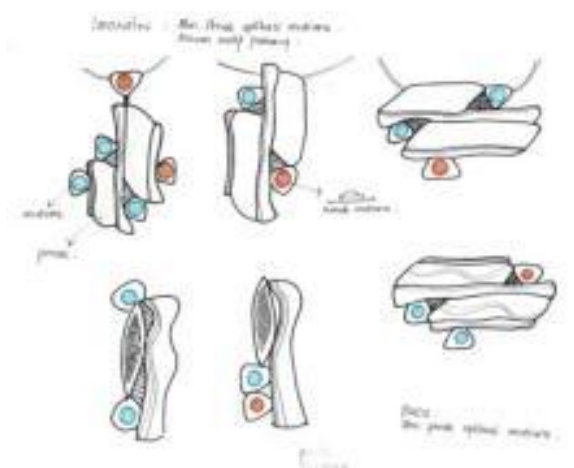

Gb.14. Sketsa 1

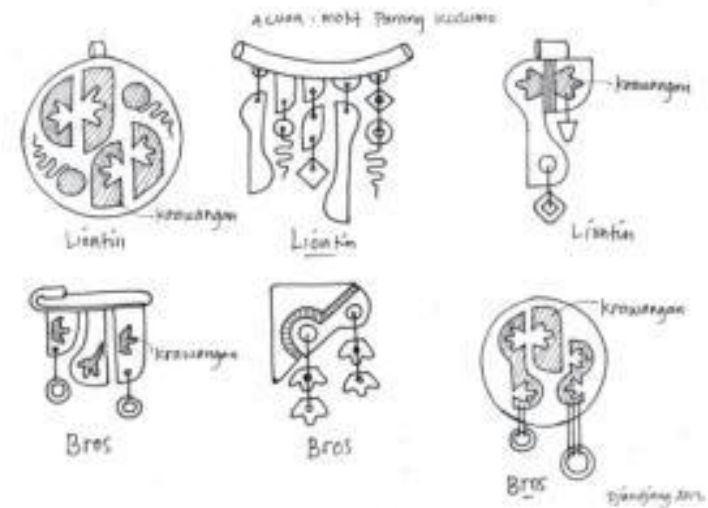

Gb.15. Sketsa 2
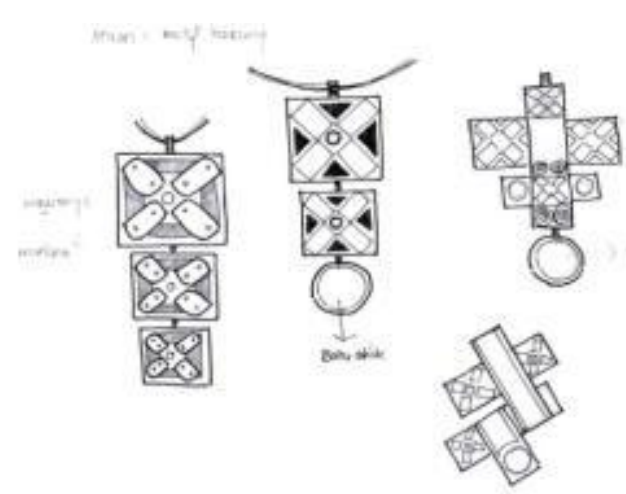

Gb.16. Sketsa 3 


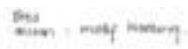

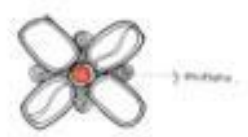

$m=$
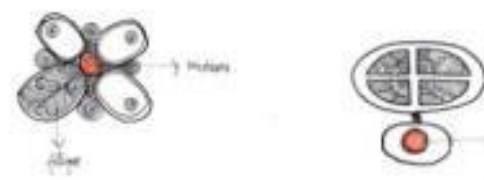

Gb. 17. Sketsa 4
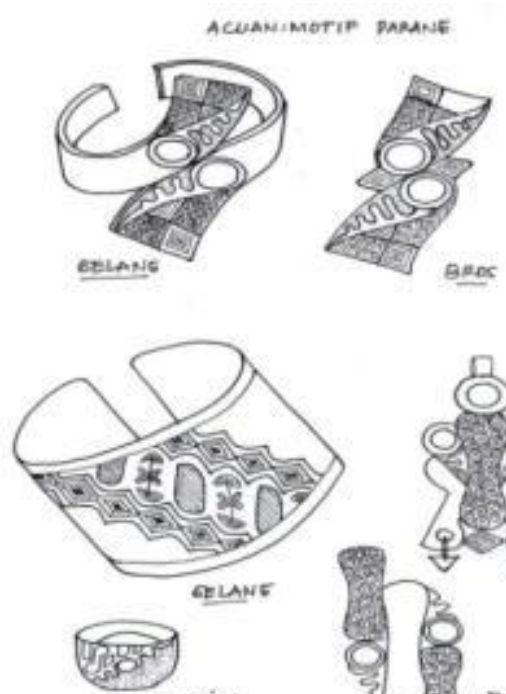

CINCiN

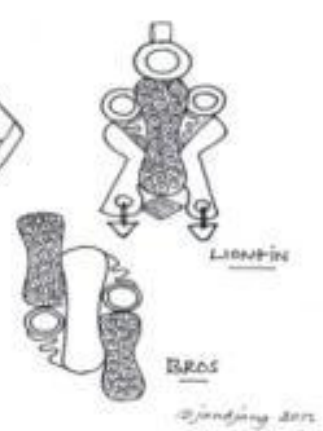

Gb. 18. Sketsa 5
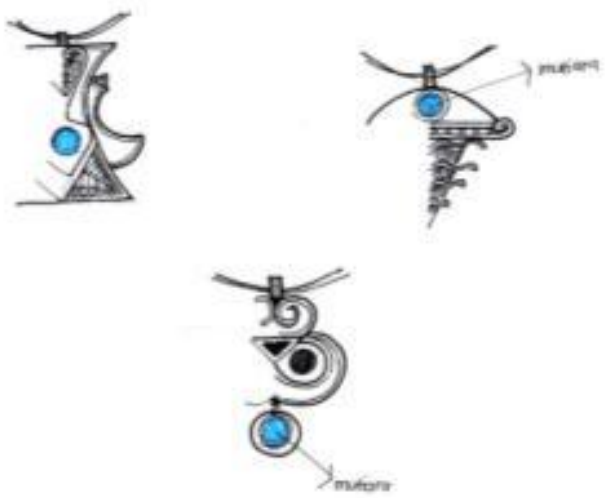

Gb. 19. Sketsa 6
2. Disain Perhiasan (3D)

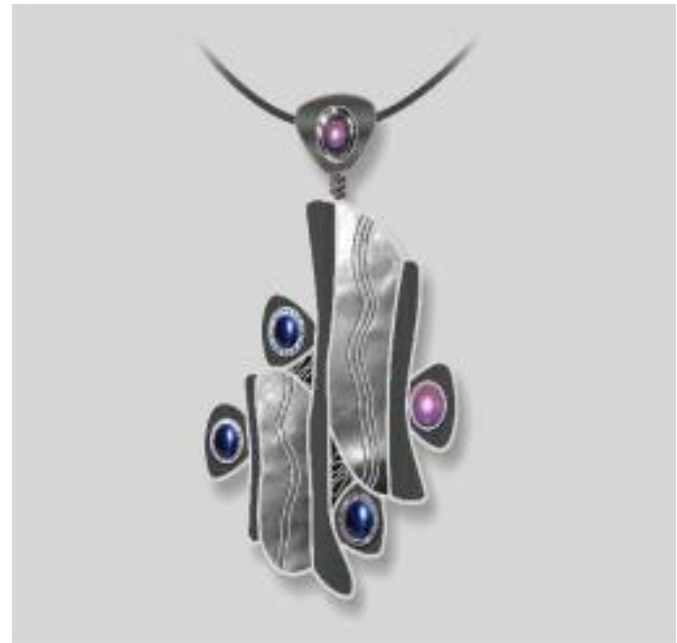

Gb. 20. Desain Perhiasan 1.

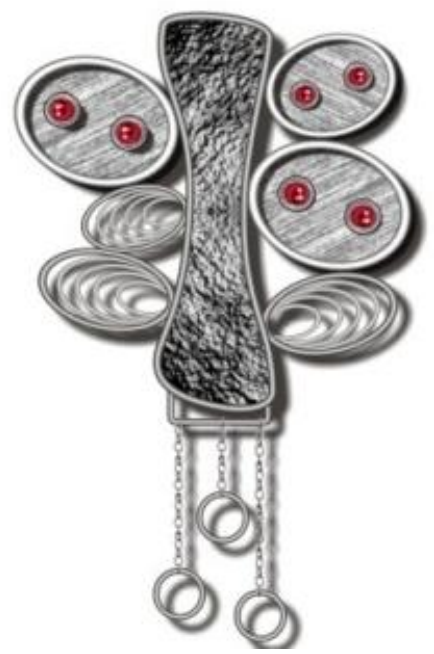

Gb. 21. Desain Perhiasan 2

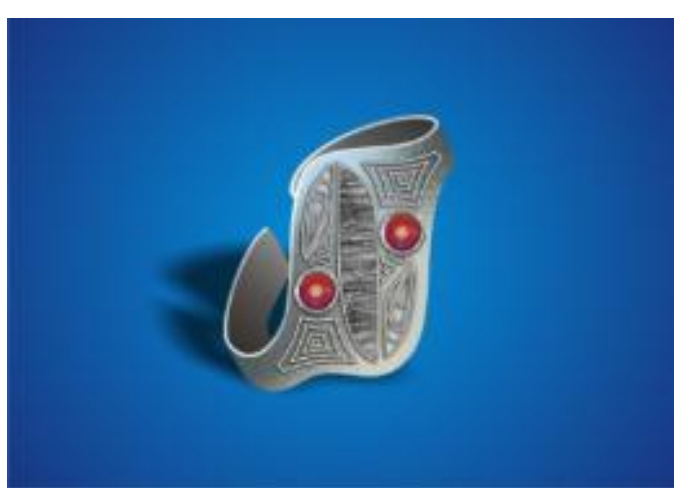

Gb. 22. Desain Perhiasan 3 


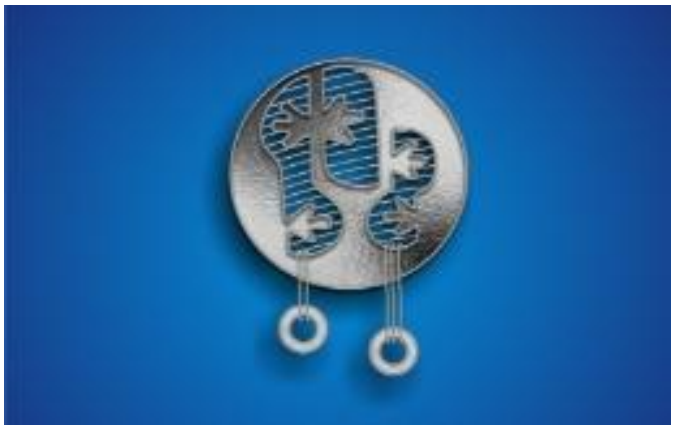

Gb. 23. Desain Perhiasan 4

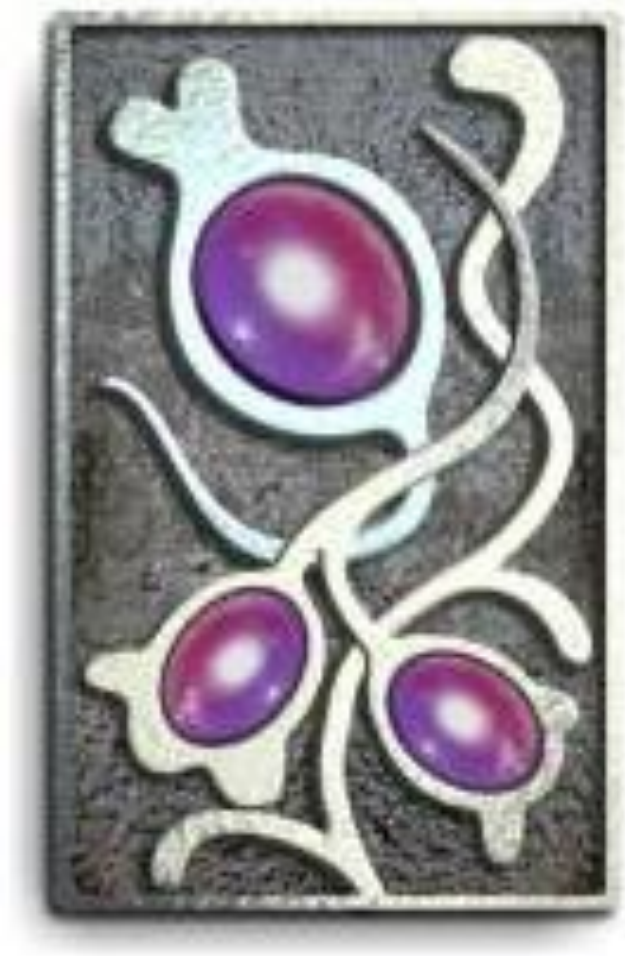

Gb. 24. Desain Perhiasan 5

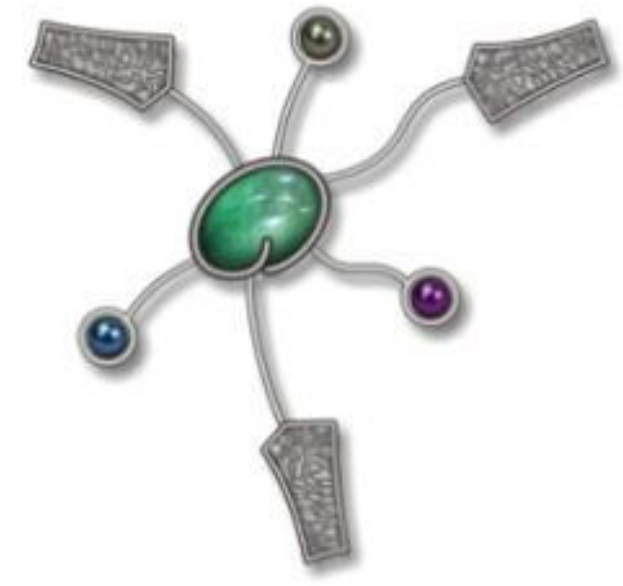

Gb. 25. Desain Perhiasan 6

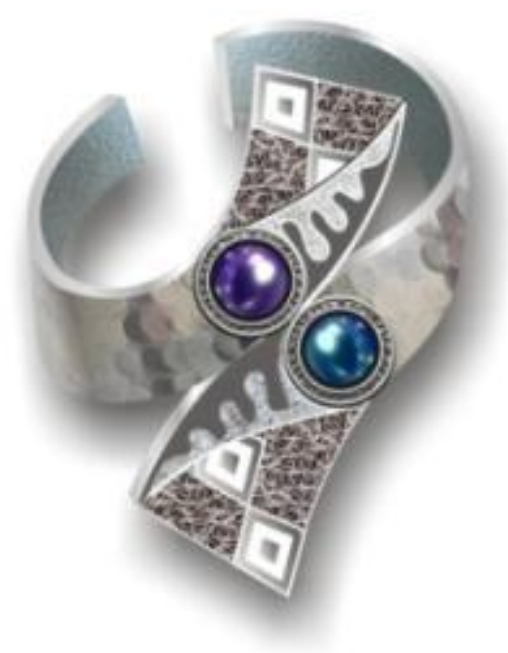

Gb. 26. Desain Perhiasan 7

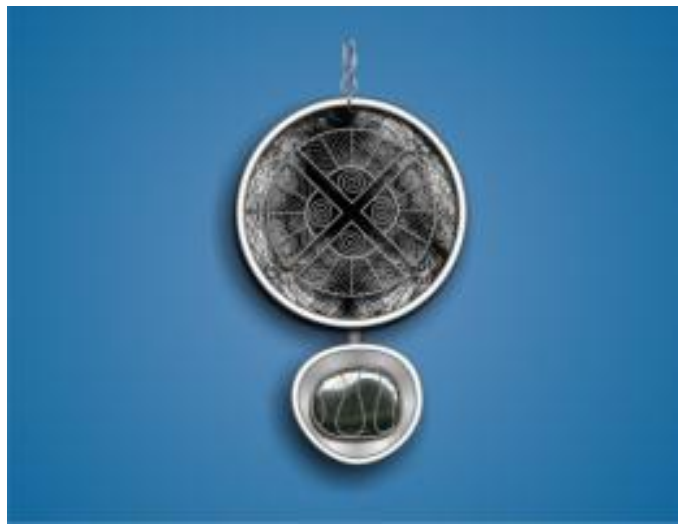

Gb. 27. Desain Perhiasan 8 
PERHIASAN KOTAGEDE

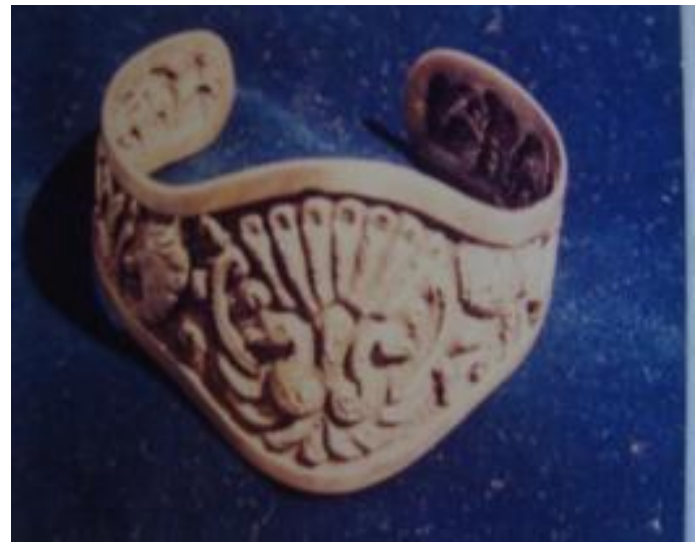

Gb. 28. Gelang Tatahan

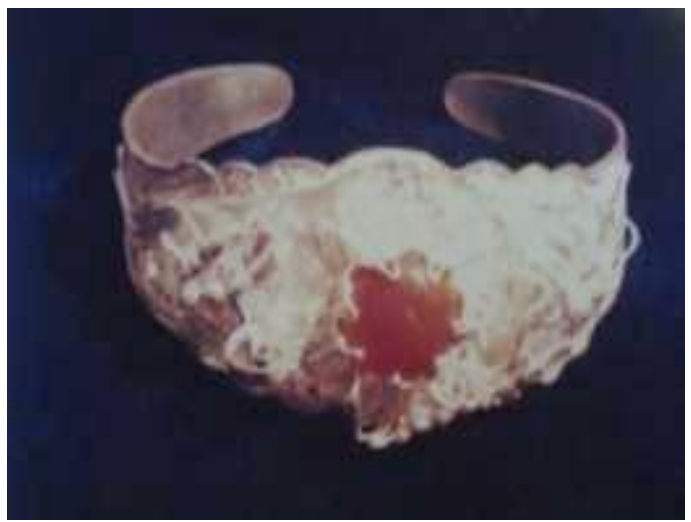

Gb. 29. Gelang Filigri

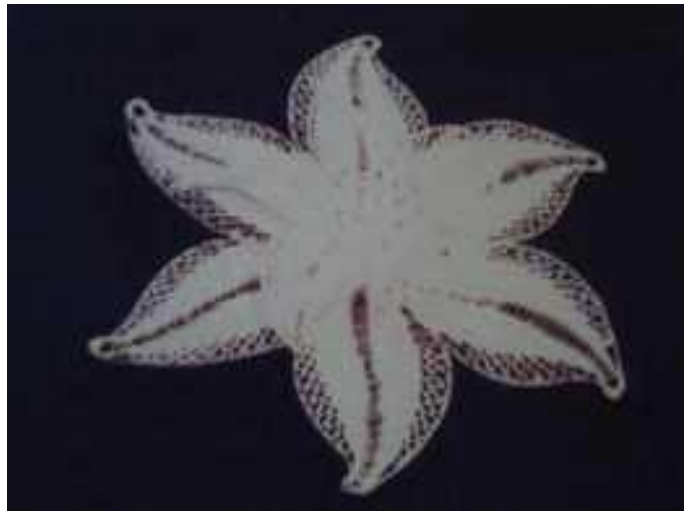

Gb.30. Bros Filigri

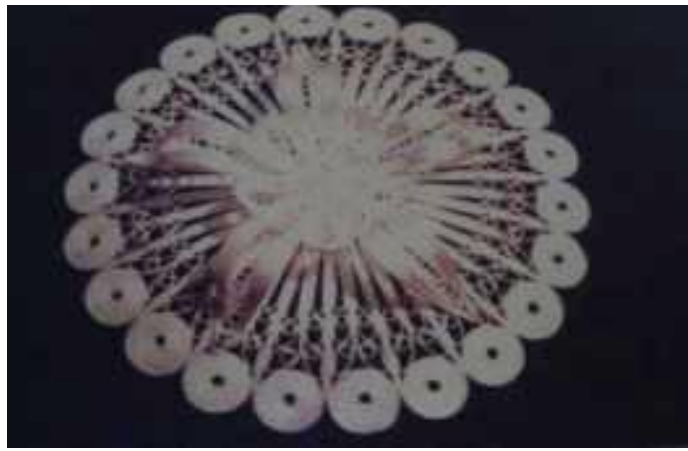

Gb.31. Bros Filigri

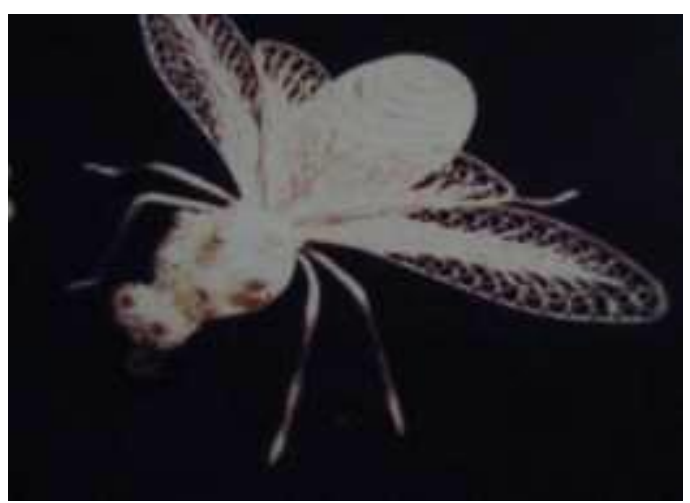

Gb.32. Bros Filigri

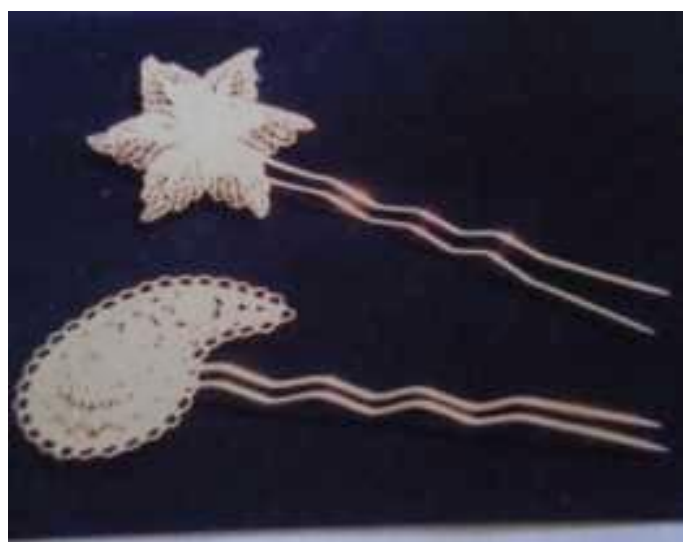

Gb. Tusuk Konde Filigri

\section{DAFTAR PUSTAKA}

Biranul Anas," Indonesia Indah",Yayasan Harapan Kita, 1997.

Buchori Z., Iman, "Aspek Disain dalam Produk Kriya " dalam Seminar 
Kriya 1990, Institut Seni Indonesia Yogyakarta, 28-29 Mei 1990, di Hotel Ambarukmo Yogyakarta.

Choate, Sharr, "Creative Gold and Silvermithing", New York, Crawn Publisher, 1974.

Condronegoro, Mari S., "Busana Adat 1877-1937 Kraton Yogyakarta: Makna dan Fungsi

Dalam Berbagai Upacara", Yayasan Pustaka Nusatama, Yogyakarta, 1995

Gustami Sp., Proses Penciptaan Seni Kriya:

Untaian Metodelogis, Program

Pascasarjana ISI

Yogyakarta, Yogyakarta, 2004

Hastanto, Sri, "Kriya Seni Kreasi ISI Yogyakarta, Sebagai Jawaban Masa Depan". Katalog Pameran KriyaSeni 2000, Galeri Nasional Indonesia, Jakarta.

McCreight, Tim, "The Complete Metalsmith", Worcester, Massachusetts, Davis Publication, 1991.

Nian S. Djoemena," Batik dan Mitra, Mitra Jambatan", Jakarta, 1990.

Siswomihardjo, Oetari, "Pola batik Klasik: Pesan Tersembunyi Yang Dilupakan", Pustaka Pelajar, Yogyakarta, 2011

Sagita, Selly, "Filligri Indonesia", 2008.
Sp., Soedarso, "Tinjauan Seni Sebuah Pengantar untuk Apresiasi Seni", Saku Dayar Sana, Yogyakarta 1990.

Suyanto, A.N., "Sejarah Batik Yogyakarta", Rumah Penerbitan Merapi kerjasama dengan Yayasan Adi Karya IKAPI Ford Foundation, 2002.

"Seni Batik Jawa: Kesamaan dan Keanekaragamannya Dari 4 daerah Propinsi di Wilayah Jawa", Lembaga Penelitian ISI Yogyakarta, 2001

\begin{tabular}{lr} 
Yogyakarta Ditinjau & Dari Aspek \\
\hline Motif Dan Makna & Simboliknya", \\
Proyek & Peningkatan \\
Pengembangan & Pendidikan \\
Tinggi, ISI Yogyakarta, Fakultas & Yeni Rupa Dan Desain, 1986
\end{tabular}

Susanto, Sewan, "Seni Kerajinan Batik Indonesia", Yogyakarta, Balai Penelitian Batik dan Kerajinan Departemen Perindustrian, 1973.

Untracht, Oppi, "Metal Teqnique for Craftsmen", Dubleday $\&$ Company, New York, 1966. 